Research Article

\title{
Neuroendocrine Neoplasms of the Gallbladder: A Clinicopathological Analysis of 13 Patients and a Review of the Literature
}

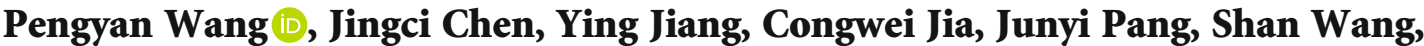 \\ and Xiaoyan Chang
}

Department of Pathology, Peking Union Medical College Hospital, Chinese Academy of Medical Sciences and Peking Union Medical College, Tsinghua University, Beijing 100730, China

Correspondence should be addressed to Xiaoyan Chang; 13683662636@163.com

Received 28 February 2021; Accepted 10 May 2021; Published 24 May 2021

Academic Editor: Oronzo Brunetti

Copyright ( 2021 Pengyan Wang et al. This is an open access article distributed under the Creative Commons Attribution License, which permits unrestricted use, distribution, and reproduction in any medium, provided the original work is properly cited.

Objectives. Mixed neuroendocrine-non-neuroendocrine neoplasms (MiNENs) are rare gallbladder neuroendocrine neoplasms (GB-NENs). This study is aimed at investigating the clinicopathological features of GB-NENs and identifying prognostic factors related to overall survival (OS) of GB-MiNENs. Methods. The clinical data and pathological features of 13 patients with GBNENs in our hospital were retrospectively reviewed. Additionally, 41 GB-MiNENs cases reported in English literature were reviewed and survival analysis was performed. Results. The mean age of thirteen patients (6 males and 7 females) with GBNENs was 57.2 years (range: 35-75 years). Two patients were diagnosed with NET grade 1 (G1), two patients with NEC (large cell/small cell $=1 / 1$ ), and nine patients with MiNENs. Of these 9 patients with MiNENs, 8 had composite tumors and 1 had amphicrine carcinoma. Microscopically, the adenocarcinoma component was located in the surface mucosa, and the neuroendocrine component was in the area of deep invasion, liver infiltration, and lymph node metastasis. Total analysis of 41 GB-MiNENs showed that patients were mainly elderly women (female/male ratio, 2.4:1.0; median age, 60 years). KaplanMeier's analysis demonstrated that liver metastasis and TNM stage III-IV were associated with decreased OS $(P<0.05)$, whereas age, sex, tumor size, grade of the neuroendocrine component, lymph node metastasis, and adjuvant chemotherapy were not significantly prognostic indicators of OS. Multivariate analysis identified liver metastasis (hazard ratio $=4.262$, 95\%confidence interval $=1.066-17.044, P=0.040)$ as an independent unfavorable prognostic factor. Conclusions. GB-MiNENs were the most common type of GB-NENs in our case series, and neuroendocrine components exhibited more aggressive lymph node metastasis and local invasion than adenocarcinoma. Liver metastasis was a poor prognostic indicator in GB-MiNENs patients.

\section{Introduction}

Neuroendocrine neoplasms (NENs) originate from disseminated neuroendocrine cells and account for approximately $0.5 \%$ of all newly diagnosed malignancies [1]. Most of these tumors are found in the gastrointestinal and respiratory systems, accounting for $66 \%$ and $31 \%$, respectively [2]. The gallbladder mucosa is absent from neuroendocrine cells except for those in the gallbladder neck region $[3,4]$, which is why NENs of the gallbladder are rare and account for only $0.5 \%$ of all NENs and $2 \%$ of all gallbladder tumors [5].
According to the World Health Organization (WHO) 2019 classification, gallbladder neuroendocrine neoplasms (GB-NENs) are divided into neuroendocrine tumors (grade 1,2 , or 3 NETs), neuroendocrine carcinomas (NECs, large cell or small cell type), and mixed neuroendocrine-nonneuroendocrine neoplasms (MiNENs) [6]. Mixed adenoneuroendocrine carcinomas (MANECs) were renamed MiNENs in the WHO 2017 classification [7]. MiNENs are neoplasms in which areas of the neuroendocrine component intermingle with areas of the non-neuroendocrine component, each comprising at least $30 \%$ of the tumor [6]. In 
TABLe 1: Clinicopathological characteristics of the 13 patients with GB-NENs.

\begin{tabular}{|c|c|c|c|c|c|c|c|}
\hline Patient & Sex/age & Presentation & $\begin{array}{c}\text { Liver } \\
\text { invasion }\end{array}$ & $\begin{array}{l}\text { Lymph node } \\
\text { metastasis }\end{array}$ & Tumor stage & Treatment & $\begin{array}{l}\text { Survival } \\
\text { (months) }\end{array}$ \\
\hline 1 & $\mathrm{M} / 57$ & $\mathrm{NO}$ & - & + & $\begin{array}{c}\text { IIIB } \\
(\mathrm{pT} 3 \mathrm{~N} 1 \mathrm{M} 0)\end{array}$ & Radical Cho & $\mathrm{D}(11)$ \\
\hline 2 & $\mathrm{~F} / 63$ & Fever & - & - & $\begin{array}{c}\text { IIB } \\
(\mathrm{pT} 2 \mathrm{bN} 0 \mathrm{M} 0)\end{array}$ & $\begin{array}{l}\text { Radical Cho, } \\
\text { Che }\end{array}$ & $\mathrm{D}(13)$ \\
\hline 3 & $\mathrm{~F} / 70$ & $\mathrm{NO}$ & - & - & $\begin{array}{c}\text { IIIA } \\
\text { (pT3N0M0) }\end{array}$ & $\begin{array}{l}\text { Radical Cho, } \\
\text { Che }\end{array}$ & $\mathrm{D}(27)$ \\
\hline 4 & $\mathrm{~F} / 53$ & Backache & + & + & $\begin{array}{c}\text { IIIB } \\
(\mathrm{pT3N1M0)}\end{array}$ & Radical Cho & $\mathrm{D}(5)$ \\
\hline 5 & $\mathrm{M} / 37$ & $\mathrm{NO}$ & - & - & $\begin{array}{c}\text { IIIA } \\
\text { (pT3N0M0) }\end{array}$ & $\begin{array}{l}\text { Radical Cho, } \\
\text { Che }\end{array}$ & $\mathrm{D}(12)$ \\
\hline 6 & $\mathrm{M} / 57$ & $\begin{array}{l}\text { Right upper abdominal } \\
\text { pain }\end{array}$ & + & - & $\begin{array}{c}\text { IIIA } \\
(\mathrm{pT} 3 \mathrm{~N} 0 \mathrm{M} 0)\end{array}$ & Radical Cho & $\mathrm{D}(3)$ \\
\hline 7 & $\mathrm{M} / 64$ & Backache & - & - & $\begin{array}{c}\text { IIB } \\
(\mathrm{pT} 2 \mathrm{bN} 0 \mathrm{M} 0)\end{array}$ & $\begin{array}{l}\text { Radical Cho, } \\
\text { Che }\end{array}$ & DFS (54) \\
\hline 8 & $\mathrm{~F} / 75$ & $\begin{array}{l}\text { Right upper abdominal } \\
\text { pain }\end{array}$ & - & - & $\begin{array}{c}\text { IIA } \\
(\mathrm{pT} 2 \mathrm{aN} 0 \mathrm{M} 0)\end{array}$ & Radical Cho & $\mathrm{D}(10)$ \\
\hline 9 & $\mathrm{~F} / 60$ & NO & - & - & $\begin{array}{c}\text { IIB } \\
(\mathrm{pT} 2 \mathrm{bN} 0 \mathrm{M} 0)\end{array}$ & Radical Cho & $\mathrm{D}(40)$ \\
\hline 10 & $\mathrm{~F} / 56$ & $\mathrm{NO}$ & + & + & $\begin{array}{c}\text { IVB } \\
(\mathrm{pT} 1 \mathrm{~N} 2 \mathrm{M} 0)\end{array}$ & $\begin{array}{l}\text { Radical Cho, } \\
\text { Che }\end{array}$ & $\mathrm{D}(15)$ \\
\hline 11 & $\mathrm{M} / 59$ & $\begin{array}{l}\text { Right upper abdominal } \\
\text { pain }\end{array}$ & - & + & $\begin{array}{c}\text { IIIB } \\
(\mathrm{pT} 3 \mathrm{~N} 1 \mathrm{M} 0)\end{array}$ & $\begin{array}{l}\text { Radical Cho, } \\
\text { Che }\end{array}$ & $\mathrm{D}(10)$ \\
\hline 12 & $\mathrm{~F} / 58$ & $\begin{array}{l}\text { Right upper abdominal } \\
\text { pain }\end{array}$ & - & - & IB (pT1bN0M0) & Cho & DFS (229) \\
\hline 13 & $\mathrm{M} / 35$ & $\begin{array}{l}\text { Right upper abdominal } \\
\text { pain }\end{array}$ & - & - & IB (pT1bN0M0) & Radical Cho & DFS (6) \\
\hline
\end{tabular}

pTNM: pathological tumor-node-metastasis; Che: chemotherapy; Cho: cholecystectomy; DFS: disease-free survival; D: death.

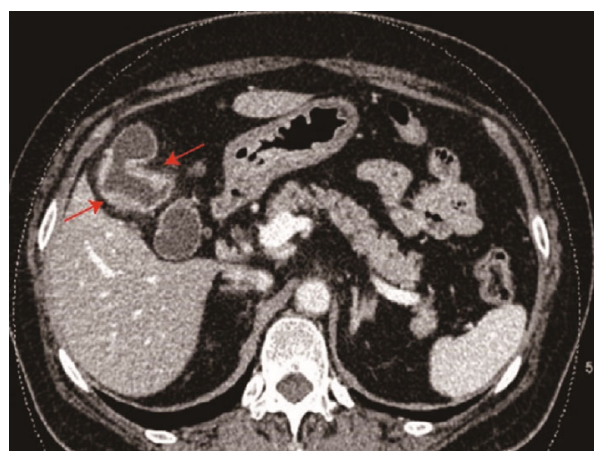

(a)

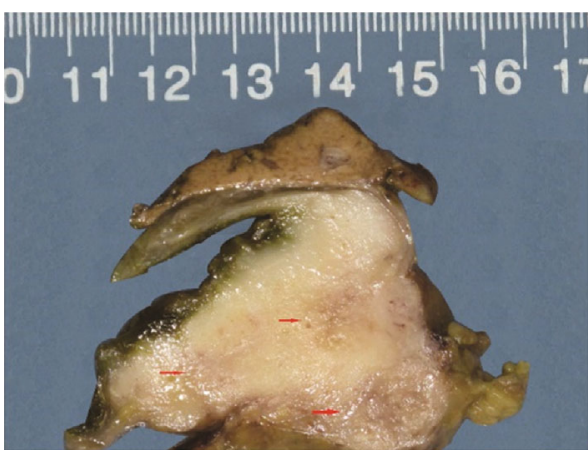

(b)

FIGURE 1: (a) An abdominal contrast-enhanced CT scan showing diffuse thickening of the gallbladder wall, with significant enhancement (arrows) in the portal venous phase. (b) Gross image of the gallbladder showing a thickened wall; the cut surface shows a tan-white thickened submucosal layer (arrows) invading through the wall into the surrounding adipose tissue, which did not invade the adjacent liver parenchyma.

1987, Lewin was the first to propose three combinations of this unique type of tumor: collision, composite, and amphicrine [8].

To date, only a few primary GB-NENs have been reported in the English language literature. The clinicopathological characteristics and prognoses for NENs of the gallbladder remain largely undetermined. Therefore, we present the pathological and clinical features of a series of 13 patients with GB-NENs and a brief literature review.

\section{Methods and Materials}

2.1. Patients and Clinicopathological Characteristics. From September 2000 to December 2020, the medical records of 
Table 2: Pathology of 13 patients with GB-NENs.

\begin{tabular}{|c|c|c|c|c|c|c|c|}
\hline Patient & Site & Morphology & $\begin{array}{c}\text { Tumor } \\
\text { size }\end{array}$ & $\begin{array}{l}\text { Mitotic index } \\
\text { (/10 HPFs) }\end{array}$ & $\begin{array}{l}\text { Neuroendocrine } \\
\text { tumor grade }\end{array}$ & $\begin{array}{l}\text { Neuroendocrine neoplasm } \\
\text { histologic subtype }\end{array}$ & $\begin{array}{c}\text { Adenocarcinoma } \\
\text { component }\end{array}$ \\
\hline 1 & Body & Infiltrative & 2 & 30 & MiNENs-NEC & Large cell type & $\begin{array}{c}\text { Moderately } \\
\text { differentiated }\end{array}$ \\
\hline 2 & Fundus & Infiltrative & 3.5 & 20 & MiNENs-NEC & Large cell type & $\begin{array}{l}\text { Moderately } \\
\text { differentiated }\end{array}$ \\
\hline 3 & Neck & Infiltrative & 2.5 & 20 & MiNENs-NEC & Small cell type & Well differentiated \\
\hline 4 & Neck & Protruding & 4 & 50 & MiNENs-NEC & Large cell type & Well differentiated \\
\hline 5 & Body & Infiltrative & 5.5 & 40 & MiNENs-NEC & Small cell type & Well differentiated \\
\hline 6 & Fundus & Protruding & 5 & 20 & MiNENs-NEC & Large cell type & $\begin{array}{l}\text { Moderately } \\
\text { differentiated }\end{array}$ \\
\hline 7 & Body & Infiltrative & 2 & 30 & MiNENs-NEC & Small cell type & Well differentiated \\
\hline 8 & Fundus & Infiltrative & 7 & 10 & MiNENs-NET G2 & Neuroendocrine tumor & Well differentiated \\
\hline 9 & Neck & Protruding & 3 & 40 & $\begin{array}{l}\text { Amphicrine } \\
\text { carcinoma }\end{array}$ & Amphicrine carcinoma & \\
\hline 10 & Fundus & Protruding & 2 & 30 & NEC & Small cell type & Absent \\
\hline 11 & Fundus & Protruding & 4 & 40 & NEC & Large cell type & Absent \\
\hline 12 & Fundus & Protruding & 0.6 & 1 & NET-G1 & Neuroendocrine tumor & Absent \\
\hline 13 & Fundus & Protruding & 0.6 & 1 & NET-G1 & Neuroendocrine tumor & Absent \\
\hline
\end{tabular}

13 patients with GB-NENs (6 males and 7 females) were retrieved from the archive files of the Department of Pathology, Peking Union Medical College Hospital. The clinical and follow-up data were obtained from electronic medical records, from the hospital discharge summary, or through telephone inquiry. Patient data were analyzed to the last follow-up before December 1, 2020. All patients underwent a cholecystectomy to extensive surgical resections, including regional lymphadenectomy and partial liver resection. Overall survival (OS) was defined as the time from surgery to the date of death or the last follow-up. Hematoxylin and eosin (H\&E) slides and immunohistochemistry (IHC) results were reviewed by three experienced pathologists. Tumor characteristics evaluated on routine H\&E-stained slides included the tumor growth pattern, cell type, mitotic index (10/highpower fields (HPFs)), stroma, and necrosis. Other pathological features that were also examined included tumor size, gross classification (protruding or infiltrative), depth of invasion, and lymph node metastasis. Staging was determined according to the Union for International Cancer Control/American Joint Committee on Cancer (UICC/AJCC) 8th edition [9].

Based on histopathological features, the WHO (2019) classifies NENs into four categories: (1) NET G1 (mitotic count $<2 / 10 \mathrm{HPFs}$ and/or $\mathrm{Ki}-67$ index $<3 \%$ ), (2) NET G2 (mitotic count $=2-20 / 10 \mathrm{HPFs}$ and/or $\mathrm{Ki}-67$ index $=3-20 \%$ ), (3) NET G3 (mitotic count $>20 / 10 \mathrm{HPFs}$ and $/$ or $\mathrm{Ki}-67$ index $>20 \%$ ), (4) NEC (mitotic count $>20 / 10 \mathrm{HPFs}$ and/or $\mathrm{Ki}-67$ index $>20 \%$ ), and (5) MiNENs [7]. The diagnosis of MiNENs was made based on the WHO 2019 classification, which states that each tumor component comprises at least $30 \%$ of the specimen. The combinations of the neuroendocrine and adenocarcinoma components in MiNENs were classified as follows: "collision" (the two components are clearly demarcated); "combined" (the two
TABLE 3: Immunohistochemistry for GB-NENs.

\begin{tabular}{lccccccc}
\hline & Syn & CgA & Ki-67 & CD56 & CK7 & CK19 & Cytokeratin \\
\hline Case 1 & + & + & $40 \%$ & + & $\mathrm{NP}$ & + Focal & + \\
Case 2 & + & + & $85 \%$ & + & + & + Focal & + \\
Case 3 & + & + Focal & $50 \%$ & - & - & $\mathrm{NP}$ & + \\
Case 4 & + & - & $70 \%$ & - & $\mathrm{NP}$ & $\mathrm{NP}$ & + \\
Case 5 & + & + & $55 \%$ & + & $\mathrm{NP}$ & $\mathrm{NP}$ & + \\
Case 6 & + & + & $80 \%$ & - & $\mathrm{NP}$ & $\mathrm{NP}$ & + \\
Case 7 & + & + & $65 \%$ & + & $\mathrm{NP}$ & + & + \\
Case 8 & + & + & $10 \%$ & + & + & $\mathrm{NP}$ & + \\
Case 9 & + & + & $60 \%$ & + & + & $+\mathrm{Focal}$ & + \\
Case 10 & + & + & $50 \%$ & + & $\mathrm{NP}$ & $\mathrm{NP}$ & + \\
Case 11 & + & + & $60 \%$ & + & + & $\mathrm{NP}$ & + \\
Case 12 & + & + & $2 \%$ & - & $\mathrm{NP}$ & $\mathrm{NP}$ & + \\
Case 13 & + & + & $1 \%$ & $\mathrm{NP}$ & $\mathrm{NP}$ & - & $\mathrm{NP}$ \\
\hline
\end{tabular}

Syn: synaptophysin; CgA: chromogranin A; NP: not performed.

components are intimately and diffusely admixed); and "amphicrine" (both components are coexpressed in the same cells) $[8,10-12]$. This study was approved by the Institutional Review Board of Peking Union Medical College Hospital.

2.2. IHC Analyses. All 13 patients included in this study were analyzed by IHC. The immunohistochemical analysis was performed on paraffin-embedded sections on a DAKO Autostainer. The primary antibodies used in the study included synaptophysin (SP11, dilution 1:100; Thermo Fisher Scientific), chromogranin A (DAK-A3, dilution 1:100; DAKO), Ki-67 (MIB-1, dilution 1:200; DAKO), cluster of differentiation protein 56 (123C3, dilution 1:100; DAKO), CK7 (OV-TL12/30, dilution 1:400; 


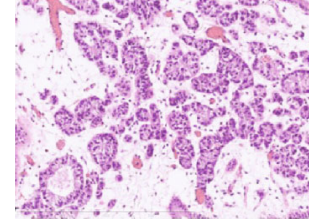

(a)

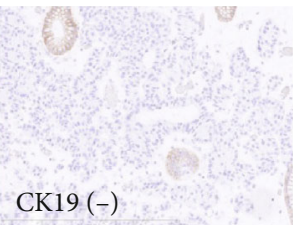

(c)

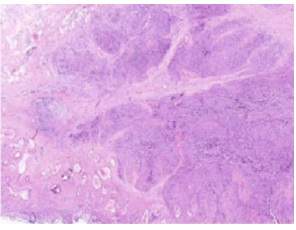

(e)

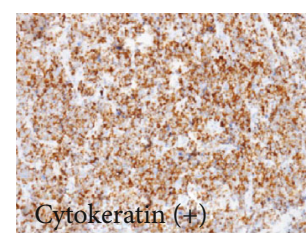

(g)

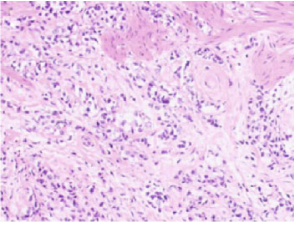

(i)

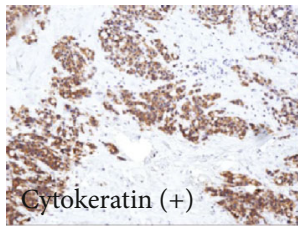

(k)

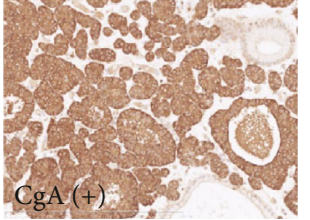

(b)

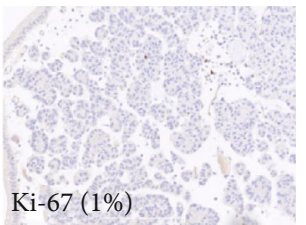

(d)

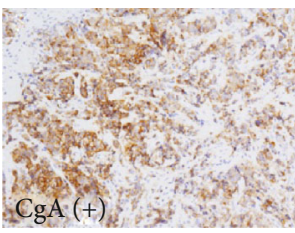

(f)

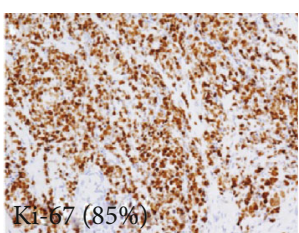

(h)

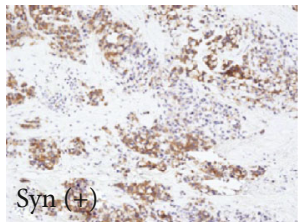

(j)

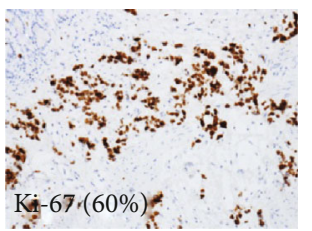

(l)

Figure 2: H\&E staining and IHC studies of GB-NENs. (a) H\&E staining of NET G1 (case 13). (b-d) IHC staining of NET G1 (case 13). (e) H\&E staining of GB-MiNENs (case 2). (f-h) IHC staining of GB-MiNENs (case 2). (i) H\&E staining of amphicrine carcinoma (case 9). (j-l) IHC staining of amphicrine carcinoma (case 9).

DAKO), CK19 (RCK 108, dilution 1:100, DAKO), and cytokeratin (AE1/AE3, dilution 1:100; DAKO). Appropriate positive and negative controls were used for all antibodies tested. For each immunohistochemical procedure, antigen retrieval was performed in a citrate buffer, and detection was amplified with the DAKO EnVision System. Mitoses were counted in at least $50 \mathrm{HPFs}\left(1 \mathrm{HPF}=2 \mathrm{~mm}^{2}\right.$ ), and the Ki-67 index was defined using the MIB antibody as the percentage of 500-2000 cells counted in areas of the strongest nuclear labeling ("hot spots") [6].
2.3. Statistical Analyses. An English literature search was performed in December 2020 to identify all of the studies that reported gallbladder mixed neuroendocrine-nonneuroendocrine neoplasms (GB-MiNENs) [4, 13-40]. SPSS version 23.0 (SPSS Inc., Chicago, IL, USA) and GraphPad Prism version 7 (GraphPad Software, CA, USA) were used for statistical analyses. The Kaplan-Meier method was used for analysis of survival data, and differences were assessed using the log-rank test. The Cox regression analyses were employed to evaluate independent prognostic 
TABLE 4: Characteristics of 41 previously reported patients with GB-MiNENs, including our current 9 patients.

Total number of patients

Sex

Median age

Primary tumor location

Tumor site

Metastatic site

Presenting symptoms

Morphology

Histopathology of the neuroendocrine component

Outcome
41

Male: 12 (12/41, 29.2\%)

Female: 29 (29/41, 70.7\%)

Female-to-male ratio: $2.4: 1$

60 years (age range: $34-85$ years) Gallbladder

Fundus: $16(16 / 29,55.2 \%)$

Body: 5 (7/29, 24.1\%)

Neck: 4 (4/29, 13.8\%)

Fundus and body: $2(2 / 29,6.9 \%)$

Lymph nodes: 15 (15/41, 36.6\%)

Liver: 17 (17/41, 41.5\%)

Duodenum: 1 (1/41, 2.4\%)

Bone: $1(1 / 41,2.4 \%)$

Abdominal pain: $22(22 / 35,62.9 \%)$

Fever: $2(2 / 35,5.7 \%)$

Back pain: $3(3 / 35,8.5 \%)$

Asymptomatic: 7 (7/35, 20.0\%)

Anorexia: $1(1 / 35,2.9 \%)$

Protruding: 27 (27/36, 75.0\%)

Infiltrative: $9(9 / 36,25.0 \%)$

SCC: $9(9 / 41,22.0 \%)$

LCNEC: 19 (19/41, 46.3\%)

SCC and LCNEC: $1(1 / 41,2.4 \%)$

NEC: $6(6 / 41,14.6 \%)$

NET: G2, 4 (4/41, 9.8\%)

Amphicrine carcinoma: 2 (2/41, 4.9\%)

Median survival: 11.5 months (range: 2-40 months)

Median disease-free survival: 12 months (range: 2-48 months) factors associated with GB-MiNENs. $P<0.05$ was considered statistically significant.

\section{Results}

3.1. Clinicopathological Information. Thirteen patients diagnosed with GB-NENs were evaluated in the current study. Their clinical characteristics are summarized in Table 1. Among the 13 patients, 6 were males, and 7 were females with a male-to-female ratio of $1: 1.2$. The mean age at diagnosis was 57.2 years (range $35-75$ years). The imaging studies, such as ultrasound examination, contrast-enhanced computed tomography (CT) scanning, and magnetic resonance imaging (MRI), showed that eight patients had intramural protruding masses. Specifically, 5 patients had gallstones with diffuse thickening of the gallbladder wall, and 3 patients presented in an advanced stage with infiltration of the liver parenchyma (Figure 1(a)).

Histological features are listed in Table 2, and immunohistochemical data are provided in Table 3. Grossly, these tumors measured 0.6 to $7 \mathrm{~cm}$ in the greatest dimension and were gray-white to yellow with clear, identifiable boundaries
(Figure 1(b)). Lesions are situated in the fundus of the gallbladder in 7 patients, in the body in 3 patients, and in the neck in 3 patients. Microscopically, two patients had NET G1, two patients had NEC (large cell/small cell $=1 / 1$ ), and nine patients had MiNENs (Figure 2).

Of these 9 patients with MiNENs, 3 (33.3\%) had NEC of the small cell type (SCC), 4 (44.5\%) had histomorphology of large cell NEC (LCNEC), 1 (11.1\%) had amphicrine carcinoma, and 1 (11.1\%) had NET G2. The neuroendocrine cells were arranged in sheets with areas of a large nest, trabecula, and cord. These cells were positive for the expression of neuroendocrine markers, such as chromogranin A, synaptophysin, and CD56, but negative for epithelial markers (cytokeratins CK7 and CK19). The glandular component was composed of tubular and papillary structures formed by columnar, goblet, and Paneth-like cells, which were positive for epithelial markers but negative for neuroendocrine markers.

The present 9 patients with GB-MiNENs were classified as follows: composite tumors (8 patients) and amphicrine carcinoma (1 patient). Of the 8 patients with composite tumors, 5 patients had mainly neuroendocrine components, 
and 3 patients had adenocarcinoma components. The two components were closely intermingled and difficult to separate in most of the lesions. Both components invaded through the adventitia with the deeper infiltrating tumor exhibiting strong expression of the neuroendocrine markers chromogranin and synaptophysin. In two of the eight patients (patients 4 and 6), the neuroendocrine carcinoma had directly invaded into liver parenchyma. Furthermore, the neuroendocrine components of patients 4 and 1 were involved in lymph node metastasis. There was 1 amphicrine carcinoma (patient 9) that was predominantly composed of nests of cells with moderate atypia, finely and spotted nuclei, and focal mucin lakes, which exhibited concurrent neuroendocrine and nonendocrine differentiation (Figure 2).

3.2. Immunohistochemical Analysis. Immunohistochemistry for GB-NENs is shown in Table 3. Immunohistochemical examinations showed positivity rates of $100 \%$ for synaptophysin, $92.3 \%$ for chromogranin A, and $66.7 \%$ for CD56. All the patients showed positive Ki-67 staining by IHC with a range of $1 \%$ to $85 \%$. In addition, almost every amphicrine carcinoma tumor cell (patient 9) showed diffuse and strong expression of synaptophysin and chromogranin A and low immunoreactivity of cytokeratin. The Ki-67 labeling index was $60 \%$.

3.3. Treatment Outcomes. Follow-up was available in 13 patients with a median survival of 11.5 months (3-40 months) (Table 1). Six patients received adjuvant chemotherapy, and 4 patients refused treatment. Two patients with NET G1 (patients 12 and 13) had no recurrence during 213-month and 6-month follow-up periods, respectively, after cholecystectomy without adjuvant therapy. Patient 7 underwent radical cholecystectomy and received six cycles of chemotherapy using cisplatin and etoposide; this patient exhibited disease-free survival (DFS) after a 54-month follow-up period. The remaining patients died of tumor progression with or without adjuvant treatment; however, the patient with amphicrine carcinoma did not undergo chemotherapy and died due to recurrence 40 months after surgery, which was much longer than the median survival time of patients with GB-MiNENs (11.5 months).

3.4. Total Analysis with Cases Reported in the Literature. We reviewed the clinical presentation and management of 41 patients with MiNENs of the gallbladder in the published literature as well as 9 patients from our institute, as shown in Table 4 [4, 13-40]. According to our data, GB-MiNENs were more frequent in females than males (female/male ratio, $2.4: 1.0$ ), and the median age at presentation was 60.0 years (range 34 to 85 years). Most of the patients presented with abdominal pain (62.9\%), followed by asymptomatic cases $(20.0 \%)$. The tumors were commonly reported to be in the fundus $(55.2 \%)$ of the gallbladder. The diameters of the tumors ranged from $1.0 \mathrm{~cm}$ to $15.0 \mathrm{~cm}$ (mean size $4.9 \mathrm{~cm}$ ), which usually present as nodular masses (75.0\%). Approximately $38.5 \%$ of the reported cases had gallstones. Nineteen of $41(46.3 \%)$ cases were large cell type (LCNEC), which
TABLE 5: The Kaplan-Meier analysis of the overall survival of GBMiNENs patients.

\begin{tabular}{lccc}
\hline Variable & Group & Event & $P$ value \\
\hline \multirow{2}{*}{ Age (years) } & $<60$ & 14 & 0.300 \\
& $\geq 60$ & 16 & \\
Sex & Male & 10 & 0.238 \\
& Female & 20 & \\
Diameter & $<4.9$ & 21 & 0.695 \\
& $\geq 4.9$ & 7 & \\
Neuroendocrine component & NA & 2 & \\
\multirow{2}{*}{ Positive LN } & NET & 3 & 0.709 \\
\multirow{2}{*}{ Liver metastasis } & NEC & 27 & \\
& Yes & 8 & 0.535 \\
Tumor stage & No & 22 & \\
& Yes & 10 & $0.013^{*}$ \\
& No & 20 & \\
Adjuvant chemotherapy & I + II & 13 & $0.043^{*}$ \\
& III + IV & 15 & \\
& NA & 2 & \\
\hline
\end{tabular}

${ }^{*} P<0.05$.

was the most common type of GB-MiNENs; however, only two (4.9\%) exhibited amphicrine carcinoma in morphology and immunohistochemistry. Among the cases reporting the histology of metastases, most of the lymph node metastasis, liver infiltration, and distant metastasis were composed of the pure neuroendocrine component $[14,18,21,23,29,34,37]$.

In the subsequent prognostic analysis, the Kaplan-Meier method was used to evaluate prognostic factors, including age, sex, tumor diameter, neuroendocrine component, lymph node metastasis, liver metastasis, TNM tumor stage, and adjuvant chemotherapy, as shown in Table 5. Only thirty patients with survival data were analyzed, with a median OS of 11 months (2-27 months). Liver metastasis and TNM tumor stage were identified as significant predictors of OS (Figure 3). Univariate and multivariate regression analyses were performed to assess the factors related to OS, and liver metastasis (hazard ratio $=4.262,95 \%$ confidence interval $=$ 1.066-17.044, $P=0.040$ ) was found to be independently associated with poor survival, as shown in Table 6 .

\section{Discussion}

GB-NENs are rare but highly malignant gallbladder tumors, most of which are found after cholecystectomy for cholecystitis, surgery for a suspected biliary malignancy, or autopsy [41]. The current literature has shown that more than onethird of gallbladder NECs are combined with an adenocarcinoma component (MiNENs) [6]. By definition, MiNENs are regarded as a conceptual category and diagnosed only when both components are present in more than $30 \%$ of the tumor based on pathological examinations [6]. To date, only a few 


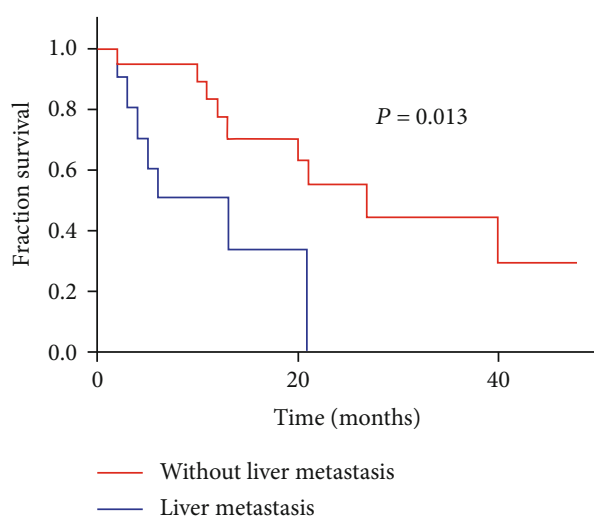

(a)

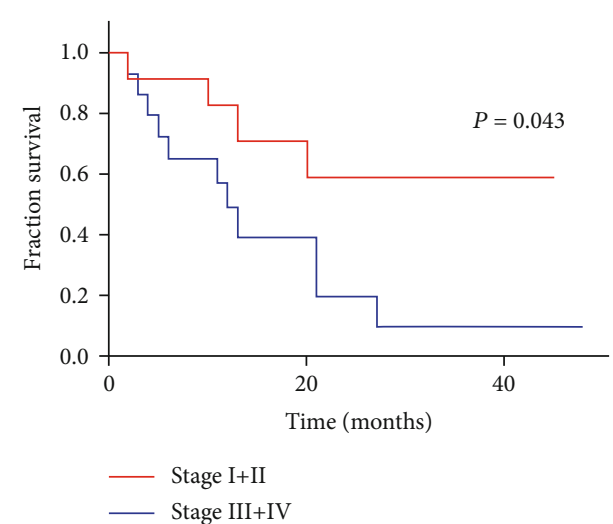

(b)

FIGURE 3: The Kaplan-Meier survival analysis shows the relationship of liver metastasis (a) and tumor stage (b) with overall survival in GBMiNENs patients.

TABLE 6: The Cox regression and univariate and multivariate analyses of GB-MiNENs.

\begin{tabular}{|c|c|c|c|c|}
\hline \multirow{2}{*}{ Parameter } & \multicolumn{2}{|c|}{ Univariate analysis } & \multicolumn{2}{|c|}{ Multivariate analysis } \\
\hline & $\operatorname{HR}(95 \% \mathrm{CI})$ & $P$ value & $\operatorname{HR}(95 \% \mathrm{CI})$ & $P$ value \\
\hline Age & $0.983(0.945-1.023)$ & 0.394 & & \\
\hline Sex (male vs. female) & $0.576(0.202-1.641)$ & 0.301 & & \\
\hline Tumor diameter & $1.295(0.904-1.855)$ & 0.159 & $1.525(0.969-2.402)$ & 0.068 \\
\hline Grade of the neuroendocrine component (NET vs. NEC) & $1.531(0.199-11.754)$ & 0.682 & & \\
\hline Lymph node metastasis (negative vs. positive) & $1.754(0.547-5.628)$ & 0.345 & & \\
\hline Liver metastasis (negative vs. positive) & $4.364(1.503-12.673)$ & $0.007^{*}$ & $4.262(1.066-17.044)$ & $0.040^{*}$ \\
\hline Tumor stage (stages I + II vs. stages III + IV) & $3.028(0.961-9.545)$ & 0.059 & $1.341(0.322-5.582)$ & 0.686 \\
\hline Adjuvant chemotherapy & $1.020(0.355-2.933)$ & 0.971 & & \\
\hline
\end{tabular}

Variables with $P<0.2$ in the univariate analysis were included in the multivariate analysis. ${ }^{*} P<0.05$.

patients with GB-NENs have been described in the literature, and even fewer with GB-MiNENs have been described.

The pathogenesis of GB-NENs remains controversial. Some researchers believe that this malignancy originates from the gastric or intestinal metaplasia of the gallbladder epithelium, which may explain the coexistence of cholecystitis and cholelithiasis in patients with GB-NENs [42]. In our study, we observed that 5 of 13 patients had gallstones with cholecystitis. However, recent studies revealed that the different components of MiNENs have similar mutation profiles, suggesting a common monoclonal origin [39, 43, 44]. In our case series, $69.2 \%$ (9/13) of gallbladder neuroendocrine neoplasms were accompanied by adenocarcinoma components, suggesting that gallbladder neuroendocrine differentiation develops from adenocarcinomas and that both components arise from a single cancer stem cell.

In 1987, Lewin [8] first proposed dividing mixed exocrine-neuroendocrine tumors into three categories: composite tumors, collision tumors, and amphicrine tumors. Fujiyoshi et al. [10] reclassified these tumors by dividing them into six categories: neuroendocrine cells interspersed within carcinomas, carcinoids (NETs) with interspersed nonendocrine cells, composite glandular-neuroendocrine cell carcinomas, collision tumors, amphicrine tumors, and combinations of the previous types. In this study, we reviewed 9 cases of gallbladder MiNENs, including 8 composite tumors and 1 amphicrine carcinoma. To the best of our knowledge, this is the second case in which amphicrine carcinoma has been reported in the gallbladder. Zhang et al. [40] presented the first case of gallbladder amphicrine carcinoma, in which the patient received surgical resection and adjuvant capecitabine chemotherapy with disease-free survival after 8 months of surgery. Regarding composite tumors, the histomorphology revealed that the surface mucosa comprised the adenocarcinoma component, and the neuroendocrine component was in the area of deep invasion, the liver and lymph node metastasis. In the GBMiNENs patients with histological information on metastases, most of the lymph node metastases, liver infiltration, and distant metastases were composed of a pure neuroendocrine component $[14,18,21,23,29,34,37]$. On the basis of these findings, the neuroendocrine component appears to be more invasive than the adenocarcinoma component.

The standard therapeutic strategy for GB-NENs has not yet been established. Surgical management remains the first choice for early-stage patients and was also offered to some advanced patients. For Tis and stage I tumors, a cholecystectomy could be enough. Chemotherapy is the first treatment option for advanced patients, and the combination of cisplatin and etoposide has been effective [45]. Furthermore, 
somatostatin analogs have also been used, with partial success [46].

At present, prognostic factors for NENs are still controversial, and the prognosis depends not only on the stage of the disease but also on the exact histological type [47]. Shi et al. considered that the survival time of patients with GBMiNENs was similar to that of patients with GB-NECs [48]. Harada et al. [21] concluded that the presence of the neuroendocrine tumor component of MiNENs in the biliary tract defines the prognosis. Moreover, most of the MiNENs cases had a high-grade neuroendocrine component, which has the tendency to invade lymph nodes and adjacent hepatic tissues, resulting in a dismal prognosis even after complete resection $[12,31]$. In our study, most tumors were diagnosed at an advanced stage, and all of the patients received surgical resection with a median survival time of 11.5 months. Similarly, one study showed that the median survival time of 20 patients with curatively resected biliary neuroendocrine tumors was 13.7 months [49]. Total analysis combined with GB-MiNENs cases reported in the literature revealed that liver metastasis and tumor stage were significant predictors of OS, and liver metastasis was an independent unfavorable prognostic factor.

The main limitation of the present study was the lack of a statistical power analysis due to the small number of patients. Additionally, some laboratory indicators should be evaluated in future investigations to improve GB-MiNENs prognosis.

\section{Conclusions}

Although there is a low incidence of GB-NENs, our results provide a good picture of the behavior of this rare condition. GB-MiNENs were the most common type in our case series. More importantly, however, the neuroendocrine component of GB-MiNENs follows an aggressive clinical course, as shown in our patients, with higher local invasion and lymph node metastasis than the adenocarcinoma. Liver metastasis was an independent negative prognostic factor for the survival of GB-MiNENs patients in this retrospective study.

\section{Data Availability}

The data used to support the findings of this study are included within the article.

\section{Conflicts of Interest}

The authors declare that they have no competing interests.

\section{Authors' Contributions}

XYC conceived and designed the study. PYW and JCC collected the clinical and follow-up information, performed the literature review, and drafted the manuscript. JYP and SW performed the immunohistochemistry staining. YJ, CWJ, and XYC participated in the histological diagnosis and immunohistochemical evaluation. All authors read and approved the final manuscript. Pengyan Wang and Jingci Chen contributed equally to this work.

\section{References}

[1] B. G. Taal and O. Visser, "Epidemiology of neuroendocrine tumours," Neuroendocrinology, vol. 80, no. 1, pp. 3-7, 2004.

[2] J. Rothenstein, S. P. Cleary, G. R. Pond et al., "Neuroendocrine tumors of the gastrointestinal tract: a decade of experience at the Princess Margaret Hospital," American Journal of Clinical Oncology, vol. 31, no. 1, pp. 64-70, 2008.

[3] E. B. Stelow, S. M. Hong, and J. H. F. Frierson, "Gallbladder and extrahepatic biliary system," in Histology for Pathologists, S. E. Mills, Ed., pp. 705-722, Academic, Philadelphia, 2007.

[4] D. Chatterjee and H. Wang, "Mixed adenoneuroendocrine carcinoma arising in a papillary adenoma of gallbladder," American Journal of Cancer Case Reports, vol. 2, no. 1, pp. 37-42, 2014.

[5] J. C. Yao, M. Hassan, A. Phan et al., "One hundred years after "carcinoid": epidemiology of and prognostic factors for neuroendocrine tumors in 35,825 cases in the United States," Journal of Clinical Oncology, vol. 26, no. 18, pp. 3063-3072, 2008.

[6] D. S. Klimstra, G. Klöppel, S. La Rosa, and G. Rindi, "Classification of neuroendocrine neoplasms of the digestive system," in WHO Classification of Tumours of Digestive System, I. D. Nagtegaal, R. D. Odze, and D. S. Klimstra, Eds., pp. 16-19, IARC, Lyon, 5th edition, 2019.

[7] G. Kloppel, A. Couvelard, R. H. Hruban, D. S. Klimstra, P. Komminoth, and R. Y. Osamura, "Introduction. Neoplasms of the neuroendocrine pancreas," in WHO Classification of Tumours of Endocrine Organs, R. V. Lloyd, R. Y. Osamura, and G. Kloppel, Eds., pp. 210-239, IARC, Lyon, 4th edition, 2017.

[8] K. Lewin, "Carcinoid tumors and the mixed (composite) glandular-endocrine cell carcinomas," The American Journal of Surgical Pathology, vol. 11, Supplement 1, pp. 71-86, 1987.

[9] M. B. Amin, S. B. Edge, F. L. Greene, C. C. Compton, J. E. Gershenwald, and R. K. Brookland, AJCC Cancer Staging Manual, Springer, New York, 8th edition, 2017.

[10] Y. Fujiyoshi, H. Kuhara, and T. Eimoto, "Composite glandular-endocrine cell carcinoma of the stomach. Report of two cases with goblet cell carcinoid component," Pathology, Research and Practice, vol. 200, no. 11-12, pp. 823-829, 2005.

[11] L. de Mestier, J. Cros, C. Neuzillet et al., "Digestive system mixed neuroendocrine-non-neuroendocrine neoplasms," Neuroendocrinology, vol. 105, no. 4, pp. 412-425, 2017.

[12] S. La Rosa, A. Marando, F. Sessa, and C. Capella, "Mixed Adenoneuroendocrine Carcinomas (MANECs) of the gastrointestinal tract: an update," Cancers, vol. 4, no. 1, pp. 11-30, 2012.

[13] M. Papotti, P. Cassoni, A. Sapino, G. Passarino, J. E. Krueger, and J. Albores-Saavedra, "Large cell neuroendocrine carcinoma of the gallbladder: report of two cases," The American Journal of Surgical Pathology, vol. 24, no. 10, pp. 14241428, 2000.

[14] A. Noske and S. Pahl, "Combined adenosquamous and largecell neuroendocrine carcinoma of the gallbladder," Virchows Archiv, vol. 449, no. 1, pp. 135-136, 2006.

[15] T. Shimizu, T. Tajiri, K. Akimaru et al., "Combined neuroendocrine cell carcinoma and adenocarcinoma of the gallbladder: report of a case," Journal of Nippon Medical School = Nippon Ika Daigaku zasshi, vol. 73, no. 2, pp. 101-105, 2006.

[16] H. Oshiro, K. Matsuo, H. Mawatari et al., "Mucin-producing gallbladder adenocarcinoma with focal small cell and large cell neuroendocrine differentiation associated with pancreaticobiliary 
maljunction," Pathology International, vol. 58, no. 12, pp. $780-$ 786, 2008.

[17] S. Iype, T. A. Mirza, D. J. Propper, S. Bhattacharya, R. M. Feakins, and H. M. Kocher, "Neuroendocrine tumours of the gallbladder: three cases and a review of the literature," Postgraduate Medical Journal, vol. 85, no. 1002, pp. 213-218, 2009.

[18] K. Sato, T. Imai, Y. Shirota, Y. Ueda, and S. Katsuda, “Combined large cell neuroendocrine carcinoma and adenocarcinoma of the gallbladder," Pathology, Research and Practice, vol. 206, no. 6, pp. 397-400, 2010.

[19] A. E. Paniz Mondolfi, D. Slova, W. Fan et al., "Mixed adenoneuroendocrine carcinoma (MANEC) of the gallbladder: a possible stem cell tumor?," Pathology International, vol. 61, no. 10, pp. 608-614, 2011.

[20] S. Russo, F. Russo, F. M. Maiello, B. Paolini, A. Carrabba, and A. De Gregorio, "Biphasic large cell neuroendocrine carcinoma-pure mucinous carcinoma of the gallbladder (MANEC): a unique combination," Pathologica, vol. 104, no. 4, pp. 185$189,2012$.

[21] K. Harada, Y. Sato, H. Ikeda et al., "Clinicopathologic study of mixed adenoneuroendocrine carcinomas of hepatobiliary organs," Virchows Archiv, vol. 460, no. 3, pp. 281-289, 2012.

[22] N. Al-Brahim and R. Albannai, "Combined large cell neuroendocrine carcinoma and adenocarcinoma of the gallbladder," Endocrine Pathology, vol. 24, no. 2, pp. 110-113, 2013.

[23] T. Abe, K. Kajiyama, N. Harimoto, T. Gion, K. Shirabe, and T. Nagaie, "Composite adeno-endocrine carcinoma of the gallbladder with long-term survival," International Journal of Surgery Case Reports, vol. 4, no. 5, pp. 504-507, 2013.

[24] M. Shintaku, K. Kataoka, and K. Kawabata, "Mixed adenoneuroendocrine carcinoma of the gallbladder with squamous cell carcinomatous and osteosarcomatous differentiation: report of a case," Pathology International, vol. 63, no. 2, pp. 113-119, 2013.

[25] Y. Meguro, N. Fukushima, M. Koizumi et al., "A case of mixed adenoneuroendocrine carcinoma of the gallbladder arising from an intracystic papillary neoplasm associated with pancreaticobiliary maljunction," Pathology International, vol. 64, no. 9, pp. 465-471, 2014.

[26] H. Chen, Y. Y. Shen, and X. Z. Ni, "Two cases of neuroendocrine carcinoma of the gallbladder," World Journal of Gastroenterology, vol. 20, no. 33, pp. 11916-11920, 2014.

[27] S. Azad, D. Shukla, A. Garg, S. S. Negi, and V. Malhotra, "Mixed adenoneuroendocrine carcinoma of the gallbladder, histopathological features," Indian Journal of Pathology \& Microbiology, vol. 58, no. 4, pp. 543-545, 2015.

[28] M. Kamboj, J. S. Gandhi, G. Gupta et al., "Neuroendocrine carcinoma of gall bladder: a series of 19 cases with review of literature," Journal of Gastrointestinal Cancer, vol. 46, no. 4, pp. 356-364, 2015.

[29] A. M. Acosta, F. S. Hamedani, A. Kajdacsy-Balla, and E. L. Wiley, "Primary mixed adenoneuroendocrine carcinoma of the gallbladder in a 55-year-old female patient: a case report and review of the literature," International Journal of Surgical Pathology, vol. 23, no. 5, pp. 414-418, 2015.

[30] W. Liu, L. Wang, X. D. He, C. Feng, X. Y. Chang, and Z. H. Lu, "Mixed large cell neuroendocrine carcinoma and adenocarcinoma of the gallbladder: a case report and brief review of the literature," World Journal of Surgical Oncology, vol. 13, no. 1, p. 114, 2015.
[31] H. J. Hu, R. X. Zhou, Y. Q. Tan et al., "Coexisting cancers: a mixture of neuroendocrine carcinoma and adenocarcinoma in the gallbladder: a case report," Medicine, vol. 95, no. 44, article e5281, 2016.

[32] Y. X. Lin, Q. B. Jia, Y. Y. Fu, and N. S. Cheng, "Mixed adenoneuroendocrine carcinoma of the gallbladder," Journal of Gastrointestinal Surgery, vol. 22, no. 8, pp. 1452-1454, 2018.

[33] J. Jung, Y. S. Chae, C. H. Kim et al., "Combined adenosquamous and large cell neuroendocrine carcinoma of the gallbladder," Journal of Pathology and Translational Medicine, vol. 52, no. 2, pp. 121-125, 2018.

[34] S. Soin, B. S. Pannu, P. T. Myint, and A. S. Dhillon, "Large cell neuroendocrine carcinoma and adenocarcinoma of gallbladder with concomitant hepatitis C infection," BMJ Case Reports, vol. 2018, 2018.

[35] A. Skalický, L. Vištejnová, M. Dubová, T. Malkus, T. Skalický, and O. Troup, "Mixed neuroendocrine-non-neuroendocrine carcinoma of gallbladder: case report," World Journal of Surgical Oncology, vol. 17, no. 1, p. 55, 2019.

[36] N. Yannakou, S. Rizos, P. Parissi-Mathiou, D. Smailis, S. Charanioti, and C. Dervenis, "Mixed (composite) glandular-endocrine cell carcinoma of the gallbladder," $H P B$ : The Official Journal of the International Hepato Pancreato Biliary Association, vol. 3, no. 1, pp. 7-9, 2001.

[37] H. Okamoto, K. Miura, T. Ogawara, H. Fujii, and Y. Matsumoto, "Small-cell carcinoma manifesting systemic lymphadenopathy combined with adenocarcinoma in the gallbladder: aggressiveness and sensitivity to chemotherapy," Journal of Gastroenterology, vol. 38, no. 8, pp. 801-805, 2003.

[38] W. Song, W. Chen, S. Zhang, J. Peng, and Y. He, "Successful treatment of gallbladder mixed adenoneuroendocrine carcinoma with neo-adjuvant chemotherapy," Diagnostic Pathology, vol. 7, no. 1, p. 163, 2012.

[39] A. Sciarra, E. Missiaglia, M. Trimech et al., "Gallbladder mixed neuroendocrine-non-neuroendocrine neoplasm (MiNEN) arising in intracholecystic papillary neoplasm: clinicopathologic and molecular analysis of a case and review of the literature," Endocrine Pathology, vol. 31, no. 1, pp. 84-93, 2020.

[40] D. Zhang, P. Li, P. Szankasi, and X. Liao, "Mixed adenoneuroendocrine carcinoma of the gallbladder, amphicrine type: case report and review of literature," Pathology, Research and Practice, vol. 216, no. 7, article 152997, 2020.

[41] I. M. Modlin, M. D. Shapiro, and M. Kidd, "An analysis of rare carcinoid tumors: clarifying these clinical conundrums," World Journal of Surgery, vol. 29, no. 1, pp. 92-101, 2005.

[42] K. M. Eltawil, B. I. Gustafsson, M. Kidd, and I. M. Modlin, "Neuroendocrine tumors of the gallbladder: an evaluation and reassessment of management strategy," Journal of Clinical Gastroenterology, vol. 44, no. 10, pp. 687-695, 2010.

[43] M. Jesinghaus, B. Konukiewitz, G. Keller et al., "Colorectal mixed adenoneuroendocrine carcinomas and neuroendocrine carcinomas are genetically closely related to colorectal adenocarcinomas," Modern Pathology, vol. 30, no. 4, pp. 610-619, 2017.

[44] M. Scardoni, E. Vittoria, M. Volante et al., "Mixed adenoneuroendocrine carcinomas of the gastrointestinal tract: targeted next-generation sequencing suggests a monoclonal origin of the two components," Neuroendocrinology, vol. 100, no. 4, pp. 310-316, 2014.

[45] R. Garcia-Carbonero, P. JImenez-Fonseca, A. Teulé, J. Barriuso, I. Sevilla, and Spanish Society for Medical 
Oncology, "SEOM clinical guidelines for the diagnosis and treatment of gastroenteropancreatic neuroendocrine neoplasms (GEP-NENs) 2014," Clinical \& Translational Oncology, vol. 16, no. 12, pp. 1025-1034, 2014.

[46] K. Oberg, G. Akerström, G. Rindi, and S. Jelic, "Neuroendocrine gastroenteropancreatic tumours: ESMO Clinical Practice Guidelines for diagnosis, treatment and follow-up," Annals of Oncology, vol. 21, Suppl 5, pp. v223-v227, 2010.

[47] D. E. Henson, J. Albores-Saavedra, and D. Code, "Carcinoma of the gallbladder. Histologic types, stage of disease, grade, and survival rates," Cancer, vol. 70, no. 6, pp. 1493-1497, 1992.

[48] H. Shi, C. Qi, L. Meng et al., "Do neuroendocrine carcinomas and mixed neuroendocrine-non-neuroendocrine neoplasm of the gastrointestinal tract have the same prognosis? A SEER database analysis of 12,878 cases," Therapeutic Advances in Endocrinology and Metabolism, vol. 11, p. 2042018820938304, 2020.

[49] J. Kim, W. J. Lee, S. H. Lee et al., "Clinical features of 20 patients with curatively resected biliary neuroendocrine tumours," Digestive and Liver Disease, vol. 43, no. 12, pp. 965-970, 2011. 